NBER WORKING PAPER SERIES

\title{
THE EFFECT OF THE STATE CHILDREN'S \\ HEALTH INSURANCE PROGRAM \\ ON HEALTH INSURANCE COVERAGE
}

\author{
Anthony T. LoSasso \\ Thomas C. Buchmueller \\ Working Paper 9405 \\ http://www.nber.org/papers/w9405
NATIONAL BUREAU OF ECONOMIC RESEARCH
1050 Massachusetts Avenue
Cambridge, MA 02138
December 2002

This research was supported by grant number K02 HS11294 from the Agency for Healthcare Research and Quality. Extremely helpful comments on earlier drafts of this paper were provided by Mireille Jacobson, Richard Lindrooth, Ithai Lurie, Bruce Meyer and seminar participants at Syracuse University, Northwestern University, and University of California, Irvine. Jhee Un Lee provided helpful research assistance. The views expressed herein are those of the authors and not necessarily those of the National Bureau of Economic Research.

(C) 2002 by Anthony T. LoSasso and Thomas C. Buchmueller. All rights reserved. Short sections of text not to exceed two paragraphs, may be quoted without explicit permission provided that full credit including, (C) notice, is given to the source. 
The Effect of the State Children's Health Insurance Program on Health Insurance Coverage Anthony T. LoSasso and Thomas C. Buchmueller NBER Working Paper No. 9405

December 2002

JEL No. I1

\section{ABSTRACT}

This paper presents the first national estimates of the effects of the SCHIP expansions on insurance coverage. Using CPS data on insurance coverage during the years 1996 through 2000, we estimate two-stage least squares regressions of insurance coverage. We find that SCHIP had a small, but statistically significant positive effect on insurance coverage. Our regression results imply that between $4 \%$ and $10 \%$ of children meeting income eligibility standards for the new program gained public insurance. While low, these estimates indicate that states were more successful in enrolling children in SCHIP than they were with prior Medicaid expansions focused on children just above the poverty line. Crowd-out of private health insurance was estimated to be in line with estimates for the Medicaid expansions of the early 1990s, between $18 \%$ and $50 \%$.

Anthony T. LoSasso

Institute for Policy Research

Northwestern University

2040 Sheridan Road

Evanston, IL 60208-4100
Thomas C. Buchmueller

Graduate School of Management

University of California, Irvine

Irvine, CA 92697-3125

and NBER

Tbuchmu@uci.edu 


\section{Introduction}

The State Children's Health Insurance Program (SCHIP) was signed into law as part of Title XXI of the 1997 Balanced Budget Act. The goal of the legislation was to increase the insurance coverage of children in the United States by extending eligibility for public insurance to children in families earning too much to qualify for Medicaid yet too little to afford private health insurance. Touted as the largest expansion in health insurance since the enactment of Medicaid in 1965, the SCHIP legislation apportioned more than $\$ 40$ billion in federal matching funds over ten years beginning in fiscal year 1998. States are allowed to use these funds to expand Medicaid eligibility, develop new insurance programs, and to increase outreach for children already eligible for public coverage.

The efficacy and cost of public insurance expansions depend critically on two factors: program take-up and the possible substitution of public coverage for private coverage-i.e., "crowd-out". A number of recent studies find low take-up rates for individuals who became eligible for public insurance through the Medicaid expansions of the late 1980s and early 1990s (Cutler and Gruber 1996; Dubay and Kenney 1997; Shore-Sheppard 1997; Yazici and Kaestner 2000; Blumberg et al. 2000; Ham and Shore-Sheppard 2001; Card and Shore-Sheppard 2001). ${ }^{1}$ Previous studies also suggest that the Medicaid expansions contributed to a decline in private insurance, though the estimated magnitude of this effect varied considerably.

Low take-up might be an even greater problem for SCHIP as many of the families made eligible for the program had little prior experience with public insurance programs, and therefore may lack good information about the program. Negative perceptions of the quality of public

\footnotetext{
${ }^{1}$ Low take-up is not unique to health insurance, but is a problem with most public programs. See Remler et al. (2001) for a recent review.
} 
health insurance and stigma related to public assistance also represent potentially serious barriers to enrollment. Evidence from the Medicaid expansions suggests that take-up falls as coverage is extended to relatively higher income families. For example, Currie and Gruber (1996) find that take-up was higher among women who gained eligibility from expansions that were targeted at families in poverty than for those who gained coverage from broader expansions. Similarly, Card and Shore-Sheppard (2001) find that expansions targeting children under the federal poverty line (FPL) led to a 10 to $15 \%$ increase in Medicaid coverage, whereas legislation extending eligibility to children with incomes up to $133 \%$ of the FPL had essentially no effect.

Since private insurance coverage increases with income, crowd-out is potentially a greater problem for SCHIP than for prior expansions of public insurance. However, in response to research showing large crowd-out effects for Medicaid, SCHIP programs were designed with explicit mechanisms intended to keep newly eligible families from dropping private coverage in favor of public insurance. Thus, whether crowd-out is more or less of a problem in the case of SCHIP as compared to the earlier Medicaid expansions is an empirical question. ${ }^{2}$

Because the program is relatively new, research on the effects of SCHIP is quite limited. Two recent studies present evidence on trends in insurance coverage for children in the early years of SCHIP implementation (Zuckerman et al. 2001; Rosenbach et al. 2001). They show that the percent insured fell slightly for children in families with incomes above $200 \%$ of FPL, while remaining relatively constant for lower income children who were more likely to be affected by SCHIP. Since coverage had been previously falling for children in the SCHIP target population

\footnotetext{
${ }^{2}$ The anti-crowd-out provisions of SCHIP may seem to render this question moot. However, research on legislation designed to prevent the substitution of Medicare for private insurance by workers over the age of 65 suggests that those rules were largely ineffective (Glied and Stabile 2001). Even if SCHIP were implemented in a way to limit direct transitions from private to public insurance, crowd-out can still occur if the program inhibits transitions from uninsurance or public insurance to private coverage.
} 
(incomes between 100 and $200 \%$ of the FPL) this suggests a positive, if small, effect of the program. Neither study attempts to calculate rates of take-up or crowd-out. Kronick and Gilmer (2001) study the effect of four state-level programs implemented prior to SCHIP on the insurance coverage of adults. They estimate that these programs were successful in enrolling between 6 and 24\% of the target population. Estimates of crowd-out vary across states and, interestingly, are larger for two states (Minnesota and Tennessee) whose programs included greater explicit protections against crowd-out. As expected, Kronick and Gilmer find greater evidence of crowd-out for adults with incomes above the FPL as compared to those below. Our study is the first to estimate the effect of SCHIP eligibility on public and private insurance coverage of children. We use 1997-2001 data from Current Population Survey (CPS) and econometric techniques similar to those used in previous research on the Medicaid expansions (e.g., Currie and Gruber 1996; Cutler and Gruber 1996; Ham and Shore-Sheppard 2001). Specifically, we use an instrumental variables approach that relies on variation in the timing and extent of coverage expansions to identify the effect of SCHIP on insurance coverage. In addition to estimating the overall effect of SCHIP eligibility on coverage by public insurance (take-up), private insurance (crowd-out), and uninsurance, we test for differences between states that implemented SCHIP by expanding Medicaid eligibility and those that established new standalone programs.

We find that the enactment of SCHIP led to a small, but statistically significant reduction in the rate of uninsurance for children. The program take-up rate implied by our results is lower than comparable estimates for the Medicaid expansions of the 1980s and 1990s as a whole, though larger than estimates pertaining to Medicaid expansions that, like SCHIP, were targeted at children above the poverty line. We find no statistically significant difference across types of 
SCHIP programs. Estimation of take-up and crowd-out effects in our data are complicated by the fact that some public health insurance plans, particularly newly created non-Medicaid programs, could be mistaken by CPS respondents for private health insurance plans. Indeed, our results provide evidence that is suggestive of such errors in reporting. Treating the CPS insurance data as accurate results in small and statistically insignificant estimates of crowd-out. In contrast, models that account for potential misreporting suggest that crowd-out represents between one-fifth and one-half of the increase in public coverage.

\section{The State Children's Health Insurance Program}

Like Medicaid, SCHIP is a joint federal-state program, though SCHIP offers states more flexibility with respect to eligibility criteria, program design, and benefits. States had three broad options for implementing SCHIP. They could expand their Medicaid programs by either increasing income eligibility thresholds or extending coverage to age groups that were not eligible for Medicaid previously, create a new separate health insurance program for children, or do both. At the time of implementation, a key argument for expanding Medicaid was that states could build on existing infrastructure for administration, enrollment, and process of claims. The main disadvantages of this approach were that it required conforming to existing federal rules that some states consider burdensome as well as the effect of any negative reputation associated with Medicaid (Hill 2000). The main argument for creating a new insurance program for children was that doing so would allow greater flexibility to design a program that better meets the needs of children in a particular state. However, a separate program must contend with potentially high costs associated with start-up and outreach. 
Table 1 summarizes how the implementation of SCHIP and the program's effect on public insurance eligibility varied across states. As of March 2001, 19 states expanded Medicaid, 15 states created a separate SCHIP program, and 17 states implemented a combination program. There was variation across states in both the extent and timing of the increases in eligibility. In addition, it is clear from Table 1 that states differed in their initial pre-SCHIP eligibility criteria and that within states eligibility rules were more generous for younger children. Prior to SCHIP, states were required to cover children 6 years of age and under up to $133 \%$ of poverty and were allowed to expand coverage up to $185 \%$ and still receive federal matching dollars. As of 1996 several states had used their own funds to expand eligibility beyond $185 \%$ of the FPL. Most states implemented their Title XXI SCHIP expansion programs in 1998. States that implemented both Medicaid expansions and a separate SCHIP program were able to start each component at different times, usually expanding Medicaid eligibility first. Since eligibility increases were larger in states that previously had lower eligibility limits for Medicaid, the SCHIP expansions have reduced the cross-state variation in public insurance eligibility standards (Ullman and Hill 2001; Cunningham 2001). However, it is clear from Table 1 that cross-state variation still exists, but within-state variation in eligibility across age groups has been largely eliminated.

Title XXI specifically states that any already-insured children, including those insured under Medicaid, are not eligible to enroll in SCHIP. In order to prevent states from shifting enrollees from Medicaid to SCHIP to take advantage of more generous Federal matching rates, the legislation requires that children who apply for SCHIP be screened for Medicaid eligibility, and those found to eligible can only enroll in Medicaid instead. Because of this rule, it is possible that SCHIP "marketing" may have indirectly increased the Medicaid enrollment of 
children who were already eligible for but not covered by that program (U.S. GAO 2000).

Because nearly $60 \%$ of children made eligible by the SCHIP expansions already had private health insurance, there was great concern about the potential substitution of public for private coverage. Strategies taken by states to reduce crowd-out include requirements that children must be without insurance for some period (typically three to twelve months) prior to enrolling, the use of sliding-scale premium contributions for families with incomes above $150 \%$ of the FPL and subsidies to encourage parents to take-up employer-based coverage when it is available.

\section{Data and Descriptive Evidence}

Our analysis is based on data from the March CPS for the years 1997 through 2001. The March CPS is the most commonly used source of data on the insurance coverage of American families. The advantages of the CPS data for our analysis include large sample sizes afforded and the fact that there is information on insurance coverage for every year during, prior to and subsequent to the enactment of SCHIP. In addition, the March CPS includes identifiers for all states and data on family income, which are necessary for imputing eligibility for public health insurance, as well as family demographic variables.

All our data are from years after 1995, when the CPS survey was redesigned to improve the quality of the health insurance data (Swartz 1997). However, even after this redesign, some problems with the insurance variables are likely to remain. While the questions refer to coverage during the prior calendar year, a number of analysts have concluded that many responses in fact reflect coverage at the time of the interview (Swartz 1986; Berger et al. 1998). Nonetheless, we 
treat the insurance variables as pertaining to the prior year. ${ }^{3}$ In addition, some research has shown that the CPS undercounts the number of people enrolled in Medicaid (Lewis, et al. 1998).

A measurement issue that is not specific to the CPS arises from the fact that the implementation of SCHIP and the growth of Medicaid managed care have blurred the distinction between public and private health insurance. Many state Medicaid programs contract with commercial health plans and it is increasingly common for insurance entities that serve only publicly insured individuals to be designed to resemble a private health plan. In addition, as noted, some states require some enrollees to pay premiums. Because of these design features many CPS respondents who are enrolled in SCHIP or Medicaid programs may legitimately consider themselves to have private insurance. The greater the extent of such misclassifications, the lower will be our estimates of both take-up and crowd-out. In an attempt to mitigate this problem, we explore two alternate dependent variables in our regressions: coverage by employer-sponsored (group) private insurance, which should be more easily distinguished from SCHIP programs that "look like" private plans, and private non-group insurance coverage, which could potentially be mistaken for some states' SCHIP expansions. ${ }^{4}$

Table 2 displays descriptive statistics for the five years of CPS data. The first three rows report the percentage of children determined to be eligible for public insurance (Medicaid or stand-alone SCHIP programs) according to the eligibility standards and their family income

\footnotetext{
${ }^{3}$ Starting with the 2000 March CPS, a verification question was asked of people who did not acknowledge having any insurance coverage throughout the previous year. The verification question resulted in $8 \%$ of apparently uninsured respondents reported that they in fact had some coverage (Nelson and Mills 2001). By including year dummies in our regression model we will be able to control for the effect of this change.

${ }^{4}$ Since March, 2000 the CPS survey questions concerning public insurance use the names of state-specific programs rather than generic terms like Medicaid or SCHIP. While this should improve the accuracy of responses, substantial ambiguity is likely to remain. Take the example of California. The CPS survey asks about enrollment in Medi-Cal (as the state's Medicaid program is called) and Healthy Families (California's SCHIP program). However, since both programs contract with a number of private health plans, parents could legitimately consider their children to be enrolled in a private plan.
} 
(adjusted by state appropriate income disregard rules) as reported in the CPS. The fact that roughly one-fifth of the children with public insurance are recorded as ineligible for such coverage indicates that there is some measurement error in our eligibility determination method. The measurement problem is likely to be caused by the fact that eligibility is determined based on monthly income while the CPS reports annual income. Thus, a family whose annual income makes them appear ineligible could have experienced a period of eligibility during the year. ${ }^{5}$ As expected, eligibility for public coverage is lowest for children with private coverage. However, the fact that the percentage of this group who meet the income eligibility standards for Medicaid or SCHIP is fairly high-21\% — underscores the fact that the potential for crowd-out is a significant concern.

Several other differences across insurance categories are apparent. Relative to the uninsured and publicly insured, children with private coverage are much more likely to be in two-parent families, to be white, to have fewer persons in the household in fair or poor health, and to be born in the United States. In terms of labor market variables, private coverage is positively associated with the number of adult workers in the household and having at least one adult who works for a large firm. The latter variable is important given the strong relationship between firm size and employer provision of health benefits.

Figures 1 through 4 summarize key time trends in insurance coverage and eligibility. Figure 1 shows that, nationally, the percentage of children eligible for public insurance increased by 12 percentage points between 1996 and 2000, from 30\% to 42\%. The percent without insurance fell from $15.1 \%$ to $12 \%$ over this period. Since public coverage decreased slightly over the period (from $21.3 \%$ to $19.9 \%$ ), these data would suggest that the decline in the

\footnotetext{
${ }^{5}$ Our estimate corresponds to the estimate reported by Cutler and Gruber (1996) indicating that $21 \%$ of the children made eligible by the Medicaid expansions were already publicly insured prior to the expansions.
} 
uninsurance rate was caused mainly by the increase in private coverage (from $66.4 \%$ to $70.6 \%$ ), caused perhaps by the strong economy.

However, these aggregate figures mask important differences in trends across income levels. Figure 2 reports data for children in families with incomes below the FPL. In 1996, over $90 \%$ were eligible for Medicaid, and by 2000 virtually $100 \%$ were eligible. Medicaid coverage for this group actually fell between 1996 and 1998, before leveling off. The decline likely reflects the effect of welfare reform, which was implemented over this period. After 1998, insurance coverage increased for poor children. Since essentially all poor children were already eligible for Medicaid over this period, this trend cannot be considered a direct effect of expanded eligibility for public insurance. Public coverage could have increased due to a "spillover" effect of SCHIP enrollment efforts, though such an explanation is not obvious from the figure, as the decline in uninsurance coincides with an increase in private coverage.

Children in families with incomes between 100 and $200 \%$ of the FPL were much more likely to be directly impacted by SCHIP. As shown in Figure 3, public eligibility for this group increased nearly fourfold from nearly $22 \%$ to slightly over $82 \%$. Public insurance coverage also increased, but by a much smaller amount: 7 percentage points, from $19 \%$ to about $26 \%$. The rate of uninsurance in this group fell from $22 \%$ to $16 \%$, while private coverage fell by one percentage point. This suggests that SCHIP was associated with an increase in public coverage with a small degree of crowd-out.

Figure 4 presents the corresponding trends for children in families earning between 200 and $400 \%$ of FPL, a group that was not the primary target of the SCHIP expansions and was not directly affected in most states. Public insurance eligibility and enrollment was quite low throughout this period, each reaching a high of roughly $8 \%$ by 2000 . Private coverage fell by 
roughly the same amount that public coverage increased (2\%), leaving the percent uninsured virtually constant during the period at nearly $9 \%$. These trends suggest that the limited growth in public enrollment due to SCHIP came from the ranks of the privately insured.

Of course, even when stratifying by income, it is difficult to draw precise inferences from such aggregate figures, as they obscure large differences across states and do not control for other factors that may have influenced insurance coverage over this period. Because there was significant variation across states in the timing of SCHIP implementation and the extent to which changes in income eligibility limits varied both across and within states, it is possible to identify the effects of SCHIP on public and private coverage in the context of a multivariate regression model that allows for long-run differences across states and national trends. The next section describes our model.

\section{Econometric Specification}

We use the repeated cross-section data from the CPS to estimate several versions of the following regression model:

$$
\text { COVERAGE }_{c i}=\alpha_{c} \text { PUBELIG }_{i}+\beta_{\mathbf{c}} \boldsymbol{X}_{\mathbf{i}}+\gamma_{\mathbf{c}} \boldsymbol{S T A T E}_{\boldsymbol{i}}+\theta_{\mathbf{c}} \boldsymbol{T I M E}_{\boldsymbol{i}}+\varepsilon_{c i},
$$

where the dependent variable COVERAGE $E_{c i}$ represents the type of health insurance under which the child is covered ( $c=$ public, private, or uninsured). The regressor of primary interest is PUBELIG, an indicator for public insurance eligibility, which is imputed using the child's age, family income and the eligibility standards effective in the child's state of residence at that time. The vector $\boldsymbol{X}$ contains demographic variables, including the child's gender, race, age, the number 
of people in the family, the number of workers in the household, and the characteristics of the household head. We include a full set of year and state dummies to account for national trends in health insurance coverage and long-standing differences across states, such as state health insurance regulations and state policies subsidizing healthcare for the uninsured, for example.

As noted, the period of our analysis follows the enactment of Federal welfare reform. Like previous legislation concerning Medicaid, the welfare reform bill included provisions to delink public health insurance and cash assistance. While the correlation between eligibility for the two programs has in fact declined over the past several decades, it remains quite strong and the decline in caseloads caused by welfare reform has contributed to a fall in Medicaid enrollment (Ku and Garrett 2000; Kronebusch 2001; Currie and Grogger 2002). A concern for our analysis is that our estimates of the effect of SCHIP will be confounded by the impact of the concurrent changes in welfare caseloads. The inclusion of year dummies in our model will capture the national average trend in caseloads. To account for additional state-year variation we also include in our model the AFDC/TANF participation rate (i.e., number of beneficiaries divided by population) in each state in each year.

The two quantities in which we are interested are the marginal take-up rate and the crowd-out effect. The marginal take-up rate is the percent of children who gain eligibility from the SCHIP expansions, and is given by the public eligibility coefficient in a regression with public insurance coverage as the dependent variable $\left(\alpha_{P U B}\right)$. Crowd-out is commonly defined as the decline in private insurance that can be attributed to the public program relative to the increase in public coverage. That is:

Crowd-Out $_{1}=\Delta$ Private $/ \Delta$ Public $=\alpha_{P R I V} / \alpha_{P U B}$, 
where the numerator on the right-hand side is the coefficient on PUBELIG from the private insurance regression and the denominator is the corresponding coefficient from the public insurance regression. Since the change in private coverage, public coverage and uninsurance must sum to zero, the degree of crowd-out can also be expressed as

$$
\text { Crowd-Out } 2=1-\Delta \text { Uninsured } / \Delta \text { Public }=1-\alpha_{\text {UNIN }} / \alpha_{\text {PUB }},
$$

where the numerator of the second term comes from the regression in which the uninsured dummy is the dependent variable. The two crowd-out measures would be equal given the identical right-hand side variables if the insurance categories were mutually exclusive. However, because respondents can report both private insurance and public coverage at some point during the year the crowd-out measures will differ.

The specification in equation (1) assumes that the effect of expanding eligibility for public coverage on a given insurance outcome is the same for states that chose to expand Medicaid as for those that established new stand-alone programs. Given the considerable debate concerning the relative merits of these different approaches, it is important to test for differences between them. This can be done by replacing PUBELIG with two variables, one that represents eligibility for Medicaid and one pertaining to eligibility for new stand-alone programs:

$$
\operatorname{COVERAGE}_{c i}=\alpha_{c 1} \text { MELIG }_{i}+\alpha_{c 2} \text { SELIG }_{i}+\beta_{\mathbf{c}} \boldsymbol{X}_{\mathbf{i}}+\gamma_{\mathbf{e}} \boldsymbol{S T A T E}_{\boldsymbol{i}}+\gamma_{\mathrm{c}} \boldsymbol{T I M E}_{\boldsymbol{i}}+v_{c i} .
$$


With this specification, we can then test whether expanding traditional Medicaid or creating a new stand-alone program was more effective in reducing uninsurance and increasing coverage. The Medicaid eligibility measure (MELIG) varies from the baseline (1996) period because more than half of states expanded Medicaid eligibility either with or without a separate program to insure children. Prior legislation also contributes to changes in Medicaid eligibility over this period. For example, between 1997 and 2000 a certain number of teenagers gained eligibility as a result of OBRA 1990, which required states to cover all poor children up to the FPL born after September 1983. The stand-alone program eligibility measure (SELIG) is zero for all observations prior to the implementation of states' new insurance programs. ${ }^{6}$

A problem with ordinary least squares estimation of these models is that public eligibility is likely to be endogenous because unobserved factors that are correlated with eligibility are likely to affect the demand for and availability of health insurance. One source of bias is unmeasured local economic conditions that lead to both higher rates of public eligibility (through an effect on income) and lower rates of private insurance coverage. This will lead to a spurious negative correlation between public insurance eligibility and private insurance coverage. It is also possible that poor health, or having a child who is in poor health, decreases labor supply and income and increases the demand for public insurance. In addition, as mentioned earlier, our eligibility variables are measured with error because income is measured imperfectly. Regressions that do not correct for endogeneity and measurement error will yield biased estimates of $\alpha$, the coefficient for public eligibility.

\footnotetext{
${ }^{6}$ Note that this approach does not rely on the ability to distinguish enrollees of Medicaid versus new separate programs, which is difficult in survey data (Dubay and Kenney 2000). Instead we attempt to decompose the respective effects of Medicaid versus new separate program eligibility on insurance coverage.
} 
To address this problem, we adopt the instrumental variables strategy used in several previous studies to estimate the effects of earlier Medicaid expansions (Currie and Gruber 1996; Cutler and Gruber 1996; Ham and Shore-Sheppard 2001). This approach instruments for public eligibility using a "simulated eligibility" measure, which represents the percentage of a nationally representative sample of children that would be eligible for public insurance in each state in each year. Specifically, we draw a random national sample of 300 children of each age from 0 through 18 and for each member of the random sample impute eligibility in each stateyear combination. We define our simulated eligibility measure as the mean imputed eligibility for each state-year-age combination. This variable represents a valid instrument because its variation is driven entirely by differences across states and years in eligibility rules. Since we condition on year and state fixed effects, our models are identified by variation in the extent and timing of SCHIP-related eligibility expansions. ${ }^{7}$

It is clear from Figures 1 through 4 that the SCHIP expansions had a strong impact on the public insurance eligibility of children in families with incomes between $100 \%$ and $200 \%$ of the FPL (hereafter, the target group) and relatively little effect on the eligibility of poorer children, who were for the most part already eligible for Medicaid, or higher income children, the vast majority of whom are still not eligible for public coverage. When equations (1) and (2) are estimated using a sample of all children, these lower and higher income children essentially serve as control groups for those in the target group. However, to the extent that the experience of children outside the target group do not represent good a counterfactual for children whose

\footnotetext{
${ }^{7}$ As noted above, one difference between SCHIP and Medicaid is that in order to limit crowd-out, states use prior insurance status as a factor in determining SCHIP eligibility. It is not possible to incorporate these provisions in our empirical eligibility algorithm. Thus, the children we classify as being eligible for SCHIP are those meeting income-related standards. Below we present rough estimates of the take-up rate measured relative to the number of uninsured children meeting the income standards.
} 
eligibility status changed as a result of SCHIP, this identification strategy is flawed. For example, even controlling for cash welfare participation rates, welfare reform may be a confounding factor for analyses that include children below the poverty line. Similarly, it may be inappropriate to assume that in the absence of SCHIP the secular trends for children in the target group would be the same as for children with much higher incomes.

To mitigate this potential problem, in addition to estimating equations (1) and (2) using a full sample of children, we also estimate models using data for children with family incomes in the $100 \%$ to $200 \%$ of FPL range. In both cases, the variation in our eligibility variables is coming mainly from children in the target group. However, when we limit the estimation sample to this group we do not restrict the effect of state and year effects (or the effects of any other variables) to be the same across the entire income distribution.

\section{Regression Results}

Linear probability model results for the full sample are displayed in Table 3. The panels correspond to three different dependent variables: indicator variables for no insurance, public insurance and private insurance. We present results for models using a single measure of public insurance eligibility (column 1, which corresponds to equation 1) and ones that allow the effect of eligibility for Medicaid and stand-alone SCHIP programs to differ (column 2, corresponding to equation 2). For the sake of brevity we do not report the coefficients on the control variables, which conform to the results of previous studies. In addition, although not reported, in the first stage regressions the effects of the simulated eligibility variable(s) on PUBELIG (or MELIG and SELIG) were highly significant with coefficients ranging from .86 to .88 . 
The coefficient for public eligibility indicates that the eligibility expansions of the late 1990s were associated with a small, but statistically significant reduction in the probability of children being uninsured (first row, first panel). The magnitude of the coefficient estimate implies that gaining eligibility for public insurance reduced a child's probability of being uninsured by 7.5 percentage points. When the dependent variable is public insurance coverage (second panel) the coefficient on PUBELIG has the opposite sign and roughly the same magnitude, implying that eligibility raises the probability of public coverage by 8.1 percentage points. The results in column 2 suggest there was little difference between Medicaid expansions and new insurance programs in terms of the effect on insurance coverage. When the outcome is uninsurance the coefficient for new programs is slightly larger in magnitude than the coefficient for expanded Medicaid programs ( -0.079 vs. -0.068$)$, while in the public insurance coverage regressions the opposite is true ( 0.067 vs. 0.083$)$. In both cases, however, the coefficients on $M E L I G$ and SELIG are not significantly different from each other. When the dependent variable is private insurance coverage (third panel) the effect of public eligibility, either pooled or separated into Medicaid and SCHIP, is effectively zero.

Table 4 reports the IV results for children in the SCHIP target group, those with incomes between $100 \%$ and $200 \%$ of FPL. The results are broadly similar to those for the full sample, though there are a few differences worth noting. As in the full sample, the coefficients on PUBELIG in the uninsurance and public insurance regressions are opposite in sign but are nearly identical in magnitude and significance. However, the estimated coefficients in the target group regressions are less than half as large in magnitude as the corresponding coefficients for the full sample: -0.035 and 0.035 compared to -0.074 and 0.081 . Compared to the full sample, the results for the target group are more suggestive of differences between the effect of Medicaid 
expansions and new stand-alone programs. In particular, the effect of expansions on the uninsurance rate suggests that the effect operated primarily through stand-alone programs. However, the effect of Medicaid expansions and new stand-alone programs did not have statistically different impacts on public insurance take-up. The finding that is most similar across the two samples that eligibility for public insurance, whether measured with a single variable or separate variables for each type of program, does not have a significant effect on private insurance coverage. $^{8}$

Taken together, the results in Tables 3 and 4 would suggest that the new public enrollment came entirely from the ranks of the uninsured-i.e., there was no crowd-out. However, as noted, there is reason to suspect that insurance coverage is mis-measured in such a way as to bias estimates of take-up and crowd-out. To the extent that parents of children enrolled in SCHIP report their coverage as private insurance, increases in SCHIP eligibility will be associated with spurious gains in private coverage, which will offset true crowd-out effects. One way to test for this type of bias is to compare the estimated effect of public insurance eligibility on two different types of private coverage: group coverage and non-group coverage. The logic of this test is that although new forms of public coverage may resemble or even by provided by private health plans, there should be less ambiguity as to whether or not the coverage is provided through the workplace. Thus, to the extent that SCHIP did crowd out private coverage but this effect was obscured by parents reporting SCHIP coverage as private, we would expect to see a positive effect of eligibility on non-group private insurance and a negative effect on group coverage.

\footnotetext{
${ }^{8}$ Our results are robust to the inclusion of state-time interaction effects, though we do not present these results.
} 
This is exactly what we observe. Table 5 presents results for non-group private coverage and group coverage. For both the full sample (columns 1 and 2) and the target group subsample (columns 3 and 4), eligibility for public insurance has a positive and statistically significant effect on non-group private coverage. Because there is no reason why being made eligible for public insurance should increase the probability a child has non-group private insurance, we interpret this result as reflecting an increase in (misreported) public coverage. Indeed, because SCHIP is a less expensive substitute for private non-group coverage, the true impact of SCHIP on private non-group should be less than or equal to zero. Our models imply that, conservatively, there was an additional 2 percentage point increase in public enrollment associated with the SCHIP expansions on top of that captured by the measured change in public coverage.

When the dependent variable is group insurance, the coefficients on the public eligibility variables are all negative. In the full sample, the estimated coefficient on PUBELIG is -.019, with a t-statistic $=1.35$. The coefficients on $M E L I G$ and $S E L I G$ have comparable magnitudes and p-values. When we limit the sample to children in the target group, the coefficients are slightly larger and achieve conventional levels of significance. These models imply that being made eligible for public insurance reduces the probability that a child is covered by group insurance by between 2 and 3 percentage points.

These measurement problems make it difficult to precisely calculate the take-up rate or the crowd-out effect. Nonetheless, under certain assumptions we can construct several measures of take-up and crowd-out associated with the SCHIP expansions and the associated changes in the number of children with particular coverage types. Table 6 displays these estimates. The estimates in the first panel correspond to the regression results reported in Tables 3 and 4, and 
are based on the assumption that insurance coverage is measured accurately in the March CPS. Using our public eligibility variable, we estimate that 12.7 million children were made incomeeligible for public insurance because of the SCHIP expansions. Thus, the $8.1 \%$ take-up rate estimated for the full sample implies that just over 1 million children gained public insurance coverage because of SCHIP. When we use the results from the target group subsample, the lower take-up rate means that the estimated number of children gaining coverage is less than half as large. These figures are low relative to the 20 to $24 \%$ marginal take-up rates for the Medicaid expansions estimated by Shore-Sheppard (1997) and Cutler and Gruber (1996), and closer to the range of estimates provided by Ham and Shore-Sheppard (2001). However, our estimates are larger than the zero take-up found by Card and Shore-Sheppard (2002) for expansions targeted at a population that is similar to the SCHIP population.

Of course, because SCHIP eligibility was also tied to prior insurance coverage, not all children meeting the program's income eligibility standards were truly eligible. Thus, these take-up rates are somewhat misleading as they overestimate the number of children foregoing public coverage for which they qualify. While it is not feasible with the CPS data to incorporate the insurance-related eligibility standards in our regression models, we can calculate a rough estimate of take-up among children meeting all eligibility requirements. This is done by removing from the denominator in the take-up calculation children meeting the SCHIP income eligibility standard who had private insurance in 1996. This adjustment yields take-up rates that are closer to those of Cutler and Gruber (1996) and Shore-Sheppard (1997). Dividing the increase in public enrollment of 1.03 million by the estimated 3.1 million uninsured children who gained SCHIP eligibility produces a hypothetical take-up rate of roughly $33 \%$. Using the lower estimated enrollment increase from the target group regressions yields a take-up rate of $14 \%$. 
When we treat the insurance variables as accurate, the point estimates for the share of new public enrollment accounted for by children who previously had private insurance ranges from $0 \%$ to $20 \%$, depending on the estimation sample and whether the ratio is calculated using the uninsured or privately insured regression results. The largest of these estimates corresponds to a total of 76,000 children.

In the second panel of Table 6 we adjust the take-up and crowd-out estimates for the possibility that the increase in non-group private insurance associated with the SCHIP eligibility expansions actually represents an increase in public coverage. To calculate an adjusted take-up rate among the income eligible we sum the effect of public eligibility on public coverage with the estimated effect on non-group. The latter effect is roughly 2 to 3 percentage points, yielding adjusted take-up rates of 5 to $10 \%$, depending on the sample used. The higher of these two estimates corresponds to a total of roughly 1.3 million children. Our adjusted measure of crowdout is based on the estimated effect of public eligibility on employer-sponsored group coverage. When we incorporate the coefficients reported in Table 4, we obtain crowd-out estimates of between 18 and 50\%. ${ }^{9}$ This is similar to the range of the estimates found by Shore-Sheppard (1997) and the largest of our point estimates is similar to Cutler and Gruber's (1996) estimate. In the full sample, the crowd-out estimates correspond to a range of 241,000 to 381,000 children who enrolled in public insurance who otherwise would have been enrolled in private insurance in the absence of the SCHIP expansions.

\footnotetext{
${ }^{9}$ These measures assume that true non-group coverage was not affected by SCHIP. If in fact some families substituted SCHIP coverage for non-group insurance, our adjusted take-up and crowd-out estimates will be understated.
} 


\section{Discussion}

This paper presents the first national estimates of the effects of the SCHIP expansions on insurance coverage. Several key findings emerge from our analysis. First, we find that SCHIP had a small, but statistically significant positive effect on insurance coverage. Our regression results imply that between $4 \%$ and $10 \%$ of children meeting income eligibility standards for the new program enrolled in public insurance. Take-up rates calculated for children who were both income-eligible and previously uninsured are considerably higher and are in line with estimated take-up rates for the Medicaid expansions of the 1980s and early 1990s. These adjusted take-up rates are probably too large, as they implicitly assume that all the new SCHIP enrollment came from the ranks of the uninsured, which our crowd-out results suggest was not the case. Nonetheless, even our lower estimates based only on income eligibility rules indicate that states were more successful in enrolling children in SCHIP than they were with prior Medicaid expansions focused on children just above the poverty line.

One possible explanation for SCHIP's greater success relative to earlier Medicaid expansions is that newly established SCHIP expansion programs were viewed more favorably by low income families than Medicaid. However, when we distinguish between states that implemented SCHIP by expanding Medicaid and those that started new programs, we find little support for this argument. Our point estimates indicate that eligibility for stand-alone SCHIP programs has a slightly more negative effect on the probability of being uninsured, but the differences between the two types of programs are not statistically significant. An alternative explanation is that as states enacted SCHIP they devoted considerable resources to outreach and marketing, and streamlined many enrollment procedures (US GAO, 2000). It is not possible with our data to assess the impact of these efforts or to compare the strategies taken by different 
states. A recent study by Aizer (2002) finds that outreach through community-based organizations and a television advertising campaign increased Medicaid take-up in California. More research in this area would be valuable.

One factor limiting SCHIP enrollment is the various policies that were enacted to prevent crowd-out, such as waiting periods and premium contributions. It is perhaps surprising that despite these policies, our results indicate that perhaps as much as half of the new SCHIP enrollment was offset by declining private coverage. There are several, overlapping explanations for this apparently counterintuitive result. First, it is important to understand that crowd-out, as measured in the repeated cross-section data we use, does not consist entirely of direct transitions from private to public coverage. Crowd-out can also be said to occur if the availability of SCHIP reduces the number of transitions in the other direction (i.e., children going off Medicaid as their family income increases), or reduces transitions from being uninsured to having private coverage. In addition, there is some evidence that state concerns regarding the initially low enrollment levels in SCHIP outweighed crowd-out concerns, in some cases resulting in states weakening their crowd-out controls (Lutzky and Hill 2001). The tension between achieving high rates of take-up for public insurance programs and limiting the substitution of public for private coverage remains an important policy issue and comparisons of alternative strategies for balancing these objectives is an important topic for future research.

Finally, our results point to a serious data problem facing researchers in this area. State efforts to make public insurance programs more attractive to eligible families and increased contracting with private health plans has blurred the line between public and private health insurance. The finding of a positive relationship between SCHIP eligibility and private nongroup coverage suggests that some CPS respondents whose children are insured through SCHIP 
report that coverage as private insurance. This ambiguity in distinguishing private and public coverage makes it difficult to use these data to track changes in type of insurance and to accurately estimate rates of take-up and crowd-out. 


\section{References}

Aizer, A., 2002. Advertising, Medicaid and Child Health: The Causes and Consequences of Failing to Use Public Health Insurance. Unpublished manuscript.

Berger, M.C., Black D.A., Scott F.A., 1998. How Well Do We Measure Employer-Provided Health Insurance Coverage? Contemporary Economic Policy 16:356-367.

Blumberg, L., Dubay, L., Norton, S., 2000. Did the Medicaid Expansions for Children Displace Private Insurance? An Analysis Using the SIPP. Journal of Health Economics 19(1): 3360.

Card, D., Shore-Sheppard, L.D., 2002. Using Discontinuous Eligibility Rules to Identify the Effects of Federal Medicaid Expansions. National Bureau of Economic Research Working Paper no. 9058.

Cunningham, P.J., 2001. Targeting Communities with High Rates of Uninsured Children. Health Affairs, Web Exclusive.

Currie, J., Grogger, J., 2002. Medicaid Expansions and Welfare Contractions: Offsetting Effects on Prenatal Care and Infant Health? Journal of Health Economics 21(2):313-335.

Currie, J., Gruber, J., 1996. Health Insurance Eligibility, Utilization of Medical Care, and Child Health. Quarterly Journal of Economics 111(2):431-466.

Cutler, D.M., Gruber, J., 1996. Does Public Insurance Crowd our Private Insurance. Quarterly Journal of Economics 112(2): 391-430.

Dubay, L., Kenney, G., 1997. Did Medicaid Expansion for Pregnant Women Crowd Out Private Coverage? Health Affairs 16(1):185-193.

Dubay, L., Kenney, G., 2000. Assessing SCHIP Effects Using Household Survey Data: Promises and Pitfalls. Health Services Research (Part III) 35(5): 112-127. 
Glied, S., Stabile, M., 2001. Avoiding Health Insurance Crowd-out: Evidence from the Medicare as Secondary Payer Legislation. Journal of Health Economics 20(2): 239-260. Ham, J.C., Shore-Sheppard, L.D., 2001. The Effect of Medicaid Expansions for Low-Income Children on Medicaid Participation and Insurance Coverage: Evidence from the SIPP. National Bureau of Economic Research Working Paper \#8063.

Hill, I., 2000. Charting New Courses for Children's Health Insurance. Policy \& Practice 58(4): $30-38$.

Kronebusch, K., 2001. Children's Medicaid Enrollment: The Impacts of Mandates, Welfare Reform and Policy Delinking. Journal of Health Politics, Policy and Law 26(6): 12231260.

Kronick, R., Gilmer, T., 2001. Insuring Low-Income Adults: Does Public Coverage Crowd Out Private? Health Affairs 21(1): 225-239.

Ku, L., Garret, A.B., 2000. How Welfare Reform and Economic Factors Affected Medicaid Participation: 1984-1996,” Assessing the New Federalism Discussion Paper.

Lewis, K., Ellwood, M., Czajka, J.L., 1998. Counting the Uninsured: A Review of the Literature. Urban Institute Occasional Paper Number 8.

Lutzky, A.W., Hill, I., 2001. Has the Jury Reached a Verdict? States' Early Experiences with Crowd Out under SCHIP,” Urban Institute Occasional Paper Number 47.

Nelson, C.T., Mills, R.J., 2001. The March CPS Health Insurance Verification Question and Its Effect on Estimates of the Uninsured. http://www.census.gov/hhes/hlthins/verif.html. Remler, D., Rachlin, J., Glied, S., 2001. What Can the Take-up of Other Programs Teach Us About How to Improve Take-up of Health Insurance Programs. National Bureau of Economic Research Working Paper \#8185. 
Rosenbach, M., Ellwood, M., Czajka, J.L., Irvin, C., Coupe, W., Quinn, B., 2001. Implementation of the State Children's Health Insurance Program: Momentum is Increasing After a Modest Start. Mathematica Policy Research, Inc.

Shore-Sheppard, L.D, 1997. Stemming the Tide? The Effect of Expanding Medicaid Eligibility on Health Insurance Coverage. University of Pittsburgh Working Paper.

Swartz, K., 1986. Interpreting the Estimates from Four National Surveys on the Number of People Without Health Insurance. Journal of Economic and Social Measurement 233242.

Swartz, K., 1997. Changes in the 1995 Current Population Survey and Estimates of Health Insurance Coverage. Inquiry 34(1): 70-79.

US GAO, 2000. Medicaid and SCHIP: Comparison of Outreach, Enrollment Practices, and Benefits. GAO/HEHS-00-86. Washington DC: GAO.

Ullman, F., Hill, I., 2001. Eligibility Under State Children's Health Insurance Programs. American Journal of Public Health 91(9):1449-1451.

Yazici, E.Y., Kaestner, R., 2000. Medicaid Expansions and the Crowding out of Private Health Insurance among Children. Inquiry 37(1):23-33.

Zuckerman, S., Kenney, G.M., Dubay, L., Haley, J., Holahan, J., 2001. Shifting Health Insurance Coverage, 1997-1999. Health Affairs 20(1):169-177. 


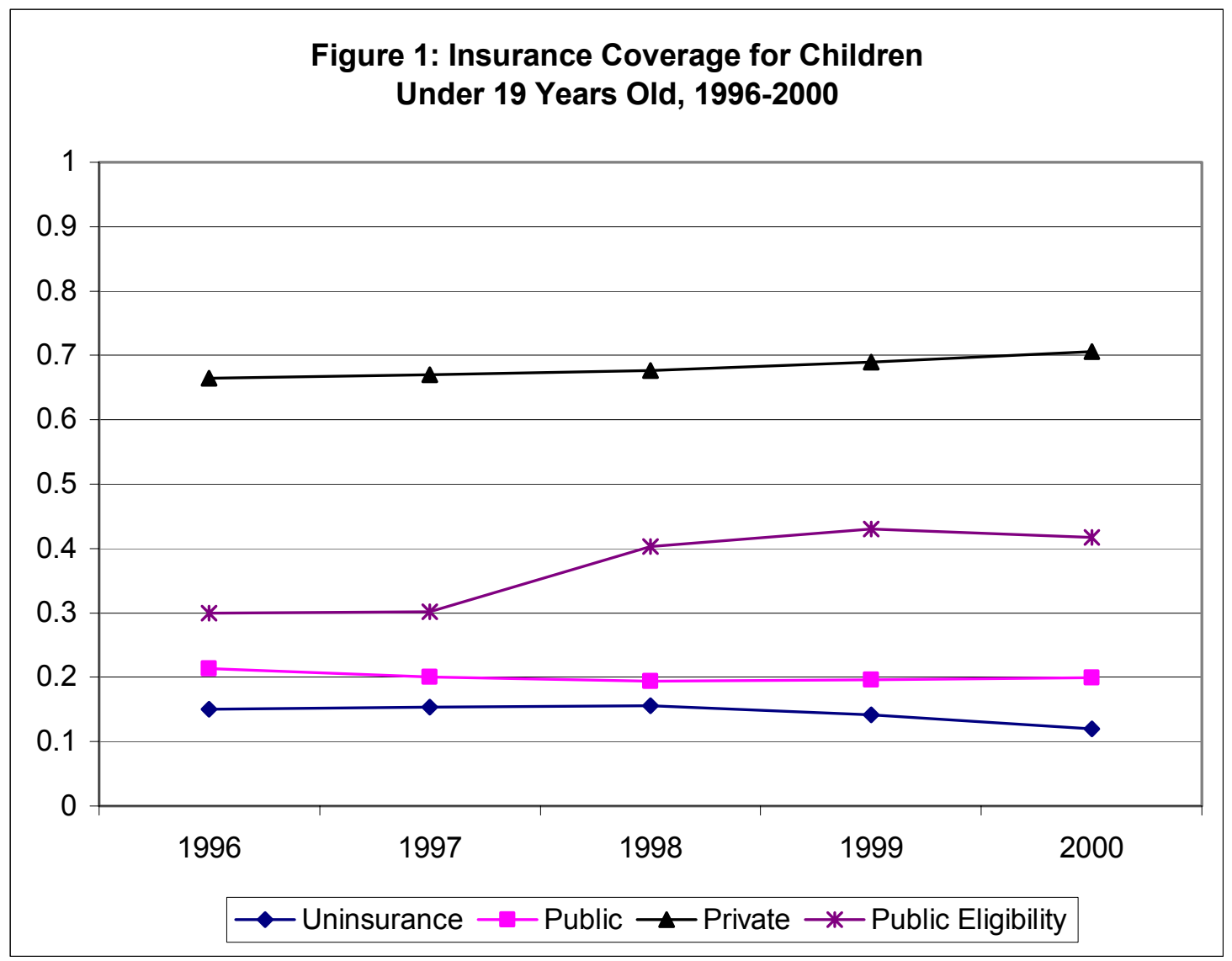

Weighted data from March CPS, years 1997-2001. 


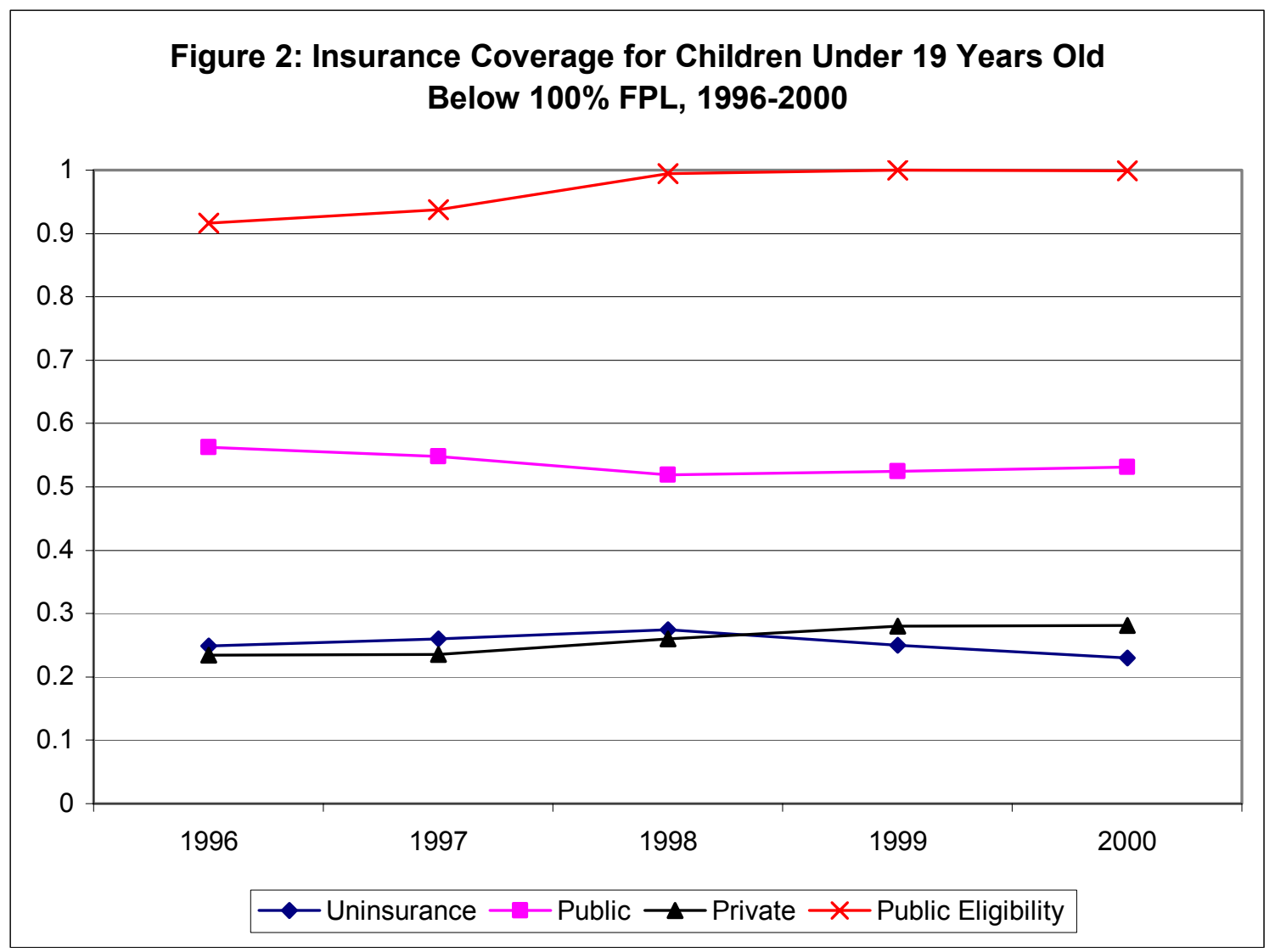

Weighted data from March CPS, years 1997-2001. 


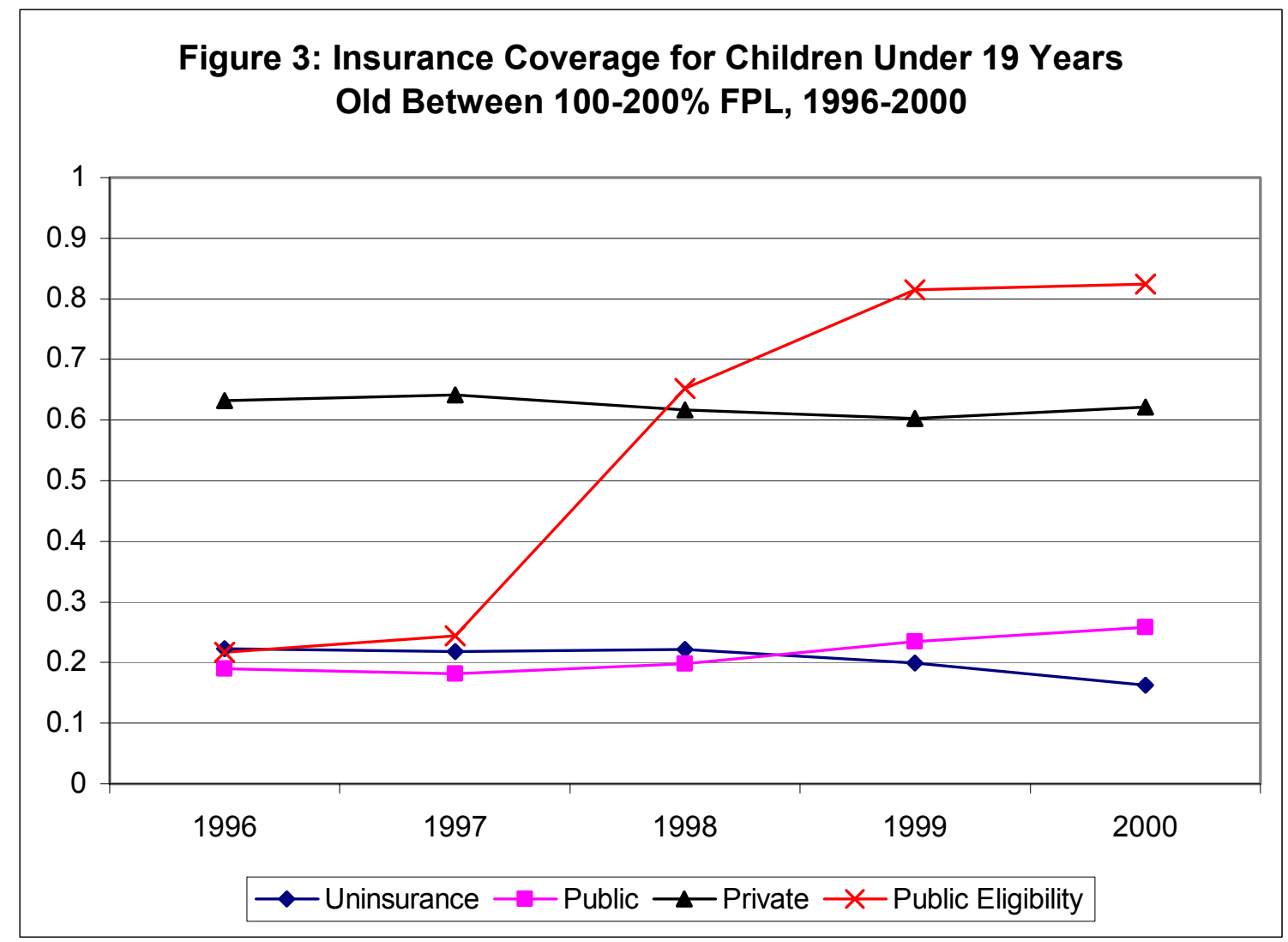

Weighted data from March CPS, years 1997-2001 


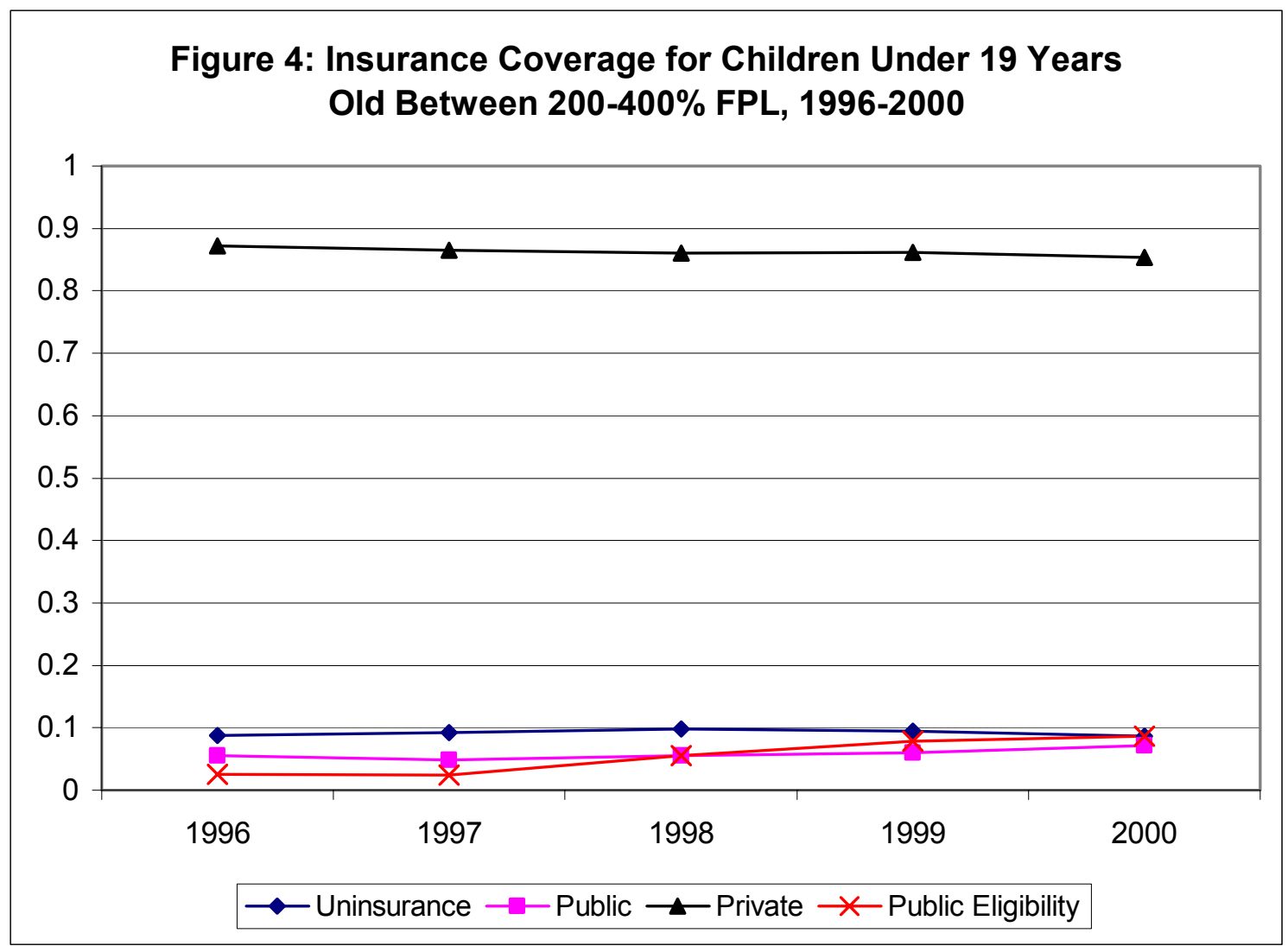

Weighted data from March CPS, years 1997-2001 
Table 1. Summary of SCHIP Expansions, by State for the Years 1996 and 2000

\begin{tabular}{|c|c|c|c|c|c|c|}
\hline \multirow[b]{2}{*}{ State } & \multirow[b]{2}{*}{$\begin{array}{c}\text { Expansion } \\
\text { Type }^{a}\end{array}$} & \multirow[b]{2}{*}{$\begin{array}{c}\text { Date } \\
\text { Implemented }\end{array}$} & \multicolumn{2}{|c|}{$\begin{array}{c}\% \text { FPL Eligibility Cutoff, } \\
1-5 \text { year olds }\end{array}$} & \multicolumn{2}{|c|}{$\begin{array}{c}\text { \% FPL Eligibility Cutoff } \\
15 \text { year olds }\end{array}$} \\
\hline & & & 1996 & 2000 & 1996 & 2000 \\
\hline $\mathrm{AK}$ & $\mathrm{M}$ & $3 / 99$ & 133 & 200 & 71 & 200 \\
\hline $\mathrm{AL}$ & $\mathrm{C}$ & $2 / 98$ & 133 & 200 & 15 & 200 \\
\hline AR & $\mathrm{M}$ & $10 / 98$ & 133 & 200 & 18 & 200 \\
\hline $\mathrm{AZ}$ & $\mathrm{S}$ & $10 / 97$ & 133 & 200 & 30 & 200 \\
\hline $\mathrm{CA}$ & $\mathrm{C}$ & $3 / 98$ & 133 & 200 & 82 & 200 \\
\hline $\mathrm{CO}$ & $\mathrm{S}$ & $4 / 98$ & 133 & 185 & 37 & 185 \\
\hline $\mathrm{CT}$ & $\mathrm{C}$ & 7/97 & 185 & 300 & 81 & 300 \\
\hline $\mathrm{DC}$ & $\mathrm{M}$ & $10 / 98$ & 133 & 200 & 50 & 200 \\
\hline $\mathrm{DE}$ & $\mathrm{S}$ & $10 / 98$ & 133 & 200 & 100 & 200 \\
\hline FL & $\mathrm{C}$ & $4 / 98$ & 133 & 200 & 28 & 200 \\
\hline GA & S & 9/98 & 133 & 200 & 100 & 200 \\
\hline HI & $\mathrm{M}$ & $1 / 00$ & 133 & 185 & 100 & 100 \\
\hline IA & $\mathrm{C}$ & $7 / 98$ & 133 & 185 & 37 & 185 \\
\hline ID & M & $10 / 97$ & 133 & 150 & 29 & 150 \\
\hline IL & M & $1 / 98$ & 133 & 185 & 46 & 185 \\
\hline IN & $\mathrm{C}$ & $10 / 97$ & 133 & 150 & 27 & 150 \\
\hline $\mathrm{KS}$ & $\mathrm{S}$ & $7 / 98$ & 133 & 200 & 100 & 200 \\
\hline KY & $\mathrm{C}$ & $7 / 98$ & 133 & 200 & 33 & 200 \\
\hline LA & M & $11 / 98$ & 133 & 150 & 10 & 150 \\
\hline MA & $\mathrm{C}$ & $10 / 97$ & 133 & 200 & 86 & 200 \\
\hline MD & M & $7 / 98$ & 185 & 200 & 40 & 200 \\
\hline $\mathrm{ME}$ & $\mathrm{C}$ & $8 / 98$ & 133 & 185 & 125 & 185 \\
\hline MI & $\mathrm{C}$ & $5 / 98$ & 150 & 200 & 150 & 200 \\
\hline $\mathrm{MN}$ & M & 9/98 & 275 & 280 & 275 & 280 \\
\hline MO & M & $10 / 97$ & 133 & 300 & 100 & 300 \\
\hline MS & $\mathrm{C}$ & $3 / 97$ & 133 & 200 & 34 & 200 \\
\hline MT & $\mathrm{S}$ & $1 / 98$ & 133 & 150 & 41 & 150 \\
\hline $\mathrm{NC}$ & S & $10 / 98$ & 133 & 200 & 100 & 200 \\
\hline ND & $\mathrm{C}$ & $10 / 98$ & 133 & 140 & 40 & 140 \\
\hline $\mathrm{NE}$ & M & $5 / 98$ & 133 & 185 & 33 & 185 \\
\hline $\mathrm{NH}$ & $\mathrm{C}$ & $5 / 98$ & 185 & 300 & 185 & 300 \\
\hline NJ & $\mathrm{C}$ & $2 / 98$ & 133 & 350 & 41 & 350 \\
\hline NM & M & $3 / 99$ & 185 & 235 & 185 & 235 \\
\hline NV & $\mathrm{S}$ & $10 / 98$ & 133 & 200 & 31 & 200 \\
\hline NY & $\mathrm{C}$ & $4 / 98$ & 133 & 192 & 51 & 192 \\
\hline $\mathrm{OH}$ & $\mathrm{M}$ & $1 / 98$ & 133 & 150 & 33 & 150 \\
\hline OK & M & $12 / 97$ & 133 & 185 & 100 & 185 \\
\hline OR & $\mathrm{S}$ & $7 / 98$ & 133 & 170 & 100 & 170 \\
\hline PA & $\mathrm{S}$ & $6 / 98$ & 133 & 200 & 41 & 200 \\
\hline RI & M & $10 / 97$ & 250 & 250 & 51 & 250 \\
\hline $\mathrm{SC}$ & M & $8 / 97$ & 133 & 150 & 48 & 150 \\
\hline SD & M & $7 / 98$ & 133 & 140 & 100 & 140 \\
\hline $\mathrm{TN}$ & M & $10 / 97$ & 400 & 400 & 100 & 400 \\
\hline
\end{tabular}

(continues) 
Table 1. Summary of SCHIP Expansions 1996 and 2000, by State (cont.)

\begin{tabular}{|c|c|c|c|c|c|c|}
\hline \multirow[b]{2}{*}{ State } & \multirow[b]{2}{*}{$\begin{array}{c}\text { Expansion } \\
\text { Type }^{a}\end{array}$} & \multirow[b]{2}{*}{$\begin{array}{c}\text { Date } \\
\text { Implemented }\end{array}$} & \multicolumn{2}{|c|}{$\begin{array}{c}\% \text { FPL Eligibility Cutoff, } \\
1-5 \text { year olds }\end{array}$} & \multicolumn{2}{|c|}{$\begin{array}{c}\% \text { FPL Eligibility Cutoff } \\
15 \text { year olds }\end{array}$} \\
\hline & & & 1996 & 2000 & 1996 & 2000 \\
\hline TX & C & $7 / 98$ & 133 & 133 & 17 & 100 \\
\hline UT & $\mathrm{S}$ & $8 / 98$ & 133 & 200 & 100 & 200 \\
\hline VA & $\mathrm{S}$ & $10 / 98$ & 133 & 185 & 100 & 185 \\
\hline VT & S & $10 / 98$ & 225 & 300 & 225 & 300 \\
\hline WA & $\mathrm{S}$ & $1 / 00$ & 200 & 250 & 200 & 250 \\
\hline WI & $\mathrm{M}$ & $4 / 99$ & 185 & 185 & 45 & 185 \\
\hline WV & $\mathrm{C}$ & $7 / 98$ & 133 & 150 & 100 & 150 \\
\hline WY & $\mathrm{S}$ & $4 / 99$ & 133 & 133 & 55 & 133 \\
\hline
\end{tabular}

${ }^{\mathrm{a}} \mathrm{M}=$ Medicaid expansion only, $\mathrm{S}=$ separate new insurance program, $\mathrm{C}=$ combination program Source: $\underline{\text { http: } / / \mathrm{cms} \text {.hcfa.gov/ }}$ 
Table 2. Descriptive Statistics of Key Variables, Stratified by Type of Insurance

\begin{tabular}{|c|c|c|c|c|}
\hline Variable & All & Uninsured & Public & Private \\
\hline Public eligible & 0.380 & 0.571 & 0.803 & 0.213 \\
\hline Medicaid eligible & 0.318 & 0.488 & 0.733 & 0.156 \\
\hline Eligible for stand-alone program & 0.062 & 0.083 & 0.071 & 0.057 \\
\hline Number of Persons in Household & $\begin{array}{c}4.210 \\
(1.480)\end{array}$ & $\begin{array}{c}4.131 \\
(1.807)\end{array}$ & $\begin{array}{c}4.245 \\
(1.806)\end{array}$ & $\begin{array}{c}4.218 \\
(1.293)\end{array}$ \\
\hline \multicolumn{5}{|l|}{ Household type } \\
\hline Two-parent household & 0.694 & 0.566 & 0.400 & 0.798 \\
\hline Male head of household & 0.055 & 0.104 & 0.059 & 0.043 \\
\hline Fem head of household & 0.251 & 0.330 & 0.541 & 0.159 \\
\hline \multicolumn{5}{|l|}{ Gender of child } \\
\hline Male & 0.512 & 0.514 & 0.509 & 0.513 \\
\hline Female & 0.488 & 0.486 & 0.491 & 0.487 \\
\hline \multicolumn{5}{|l|}{ Race } \\
\hline White & 0.627 & 0.422 & 0.400 & 0.735 \\
\hline Hispanic & 0.157 & 0.309 & 0.244 & 0.099 \\
\hline Black & 0.160 & 0.201 & 0.293 & 0.115 \\
\hline Other & 0.056 & 0.068 & 0.063 & 0.051 \\
\hline \multicolumn{5}{|l|}{ Workers in Household } \\
\hline 0 workers in household & 0.122 & 0.179 & 0.358 & 0.039 \\
\hline 1 worker in household & 0.394 & 0.457 & 0.457 & 0.367 \\
\hline $2+$ workers in household & 0.484 & 0.364 & 0.185 & 0.594 \\
\hline At least 1 person works in large firm & 0.661 & 0.460 & 0.447 & 0.764 \\
\hline \multicolumn{5}{|l|}{ Number with Some College } \\
\hline 0 persons with some college & 0.404 & 0.618 & 0.680 & 0.286 \\
\hline 1 person with some college & 0.276 & 0.243 & 0.245 & 0.294 \\
\hline $2+$ persons with some college & 0.320 & 0.139 & 0.075 & 0.420 \\
\hline Total \# in household in fair/poor health & $\begin{array}{c}0.174 \\
(0.548)\end{array}$ & $\begin{array}{c}0.206 \\
(0.599)\end{array}$ & $\begin{array}{c}0.372 \\
(0.798)\end{array}$ & $\begin{array}{c}0.115 \\
(0.429)\end{array}$ \\
\hline MSA residence & 0.779 & 0.778 & 0.756 & 0.784 \\
\hline Foreign born & 0.215 & 0.397 & 0.218 & 0.175 \\
\hline \multicolumn{5}{|l|}{ Year } \\
\hline 1996 & 0.198 & 0.206 & 0.209 & 0.192 \\
\hline 1997 & 0.199 & 0.212 & 0.199 & 0.196 \\
\hline 1998 & 0.200 & 0.217 & 0.194 & 0.199 \\
\hline 1999 & 0.201 & 0.197 & 0.197 & 0.204 \\
\hline 2000 & 0.202 & 0.168 & 0.201 & 0.209 \\
\hline Sample size & 190,257 & 29,032 & 38,906 & 127,071 \\
\hline
\end{tabular}


Table 3. The Effect of Eligibility for Public Insurance on Health Insurance Coverage, IV Results

(1) (2)

Uninsured

Eligible for public insurance

$-0.075^{* *}$

(0.012)

Eligible for Medicaid

Eligible for stand-alone program

$\mathrm{R}^{2}$

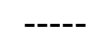

----

0.084
(2)

$-0.068 * *$

$(0.015)$

$-0.079 * *$

$(0.015)$

0.086

\section{Public Insurance}

Eligible for public insurance

$0.081 * *$

$(0.012)$

Eligible for Medicaid

Eligible for stand-alone program

$\mathrm{R}^{2}$

\section{Private Insurance}

Eligible for public insurance

Eligible for Medicaid

0.294

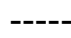

$0.082 * *$

$(0.015)$

$0.067 * *$

(0.015)

0.295

Eligible for stand-alone program

0.006

$(0.017)$

0.010

$\mathrm{R}^{2}$

0.330

$(0.018)$

0.329

Notes: Results are based on regressions using March CPS data from 1997 to 2001. Model (1) pools Medicaid and stand-alone eligibility and model (2) separates eligibility for Medicaid and stand-alone programs. All regressions control for AFDC/TANF caseload, number of person in the household, race, number of parents present and their gender, number of workers in the household, whether any in household works for a large firm ( $>50$ employees), education of parents, number of people in household in fair or poor health, MSA residence, foreign birth, age dummies for each age 1-18, time dummies, and state dummies. Standard errors in parentheses. The sample size is 190,257 .

** indicates $\mathrm{p}<0.01, *$ indicates $0.05<\mathrm{p}<0.01$ 


\section{Table 4. The Effect of Eligibility for Public Insurance on Health Insurance Coverage for Families with Income Between 100-200\% FPL, IV Results}

(1)

\section{Uninsured}

Eligible for public insurance

Eligible for Medicaid

Eligible for stand-alone program

$$
-0.035^{* *}
$$

$\begin{array}{cc}--- & -0.014 \\ & (0.012) \\ --- & -0.042 * * \\ & (0.009) \\ 0.093 & 0.094\end{array}$

\section{Public Insurance}

Eligible for public insurance

$0.035 * *$

$(0.008)$

Eligible for Medicaid

Eligible for stand-alone program

$\mathrm{R}^{2}$

\section{Private Insurance}

Eligible for public insurance

(0.010)

Eligible for Medicaid

$\begin{array}{cc}---- & -0.020 \\ & (0.014) \\ --- & -0.004 \\ & (0.010) \\ 0.138 & 0.139\end{array}$

Eligible for stand-alone program

$\mathrm{R}^{2}$

0.138
(2)

$\begin{array}{cc}--- & 0.026^{*} \\ & (0.012) \\ --- & 0.037^{* *} \\ & (0.009) \\ 0.098 & 0.097\end{array}$

Notes: Results are based on 2SLS regressions using March CPS data from 1997 to 2001. Model (1) pools Medicaid and stand-alone eligibility and model (2) separates eligibility for Medicaid and stand-alone programs. All regressions control for AFDC/TANF caseload, number of person in the household, race, number of parents present and their gender, number of workers in the household, whether any in household works for a large firm $(>50$ employees), education of parents, number of people in household in fair or poor health, MSA residence, foreign birth, age dummies for each age 1-18, time dummies, and state dummies. Standard errors in parentheses. The sample size is 42,991 .

** indicates $\mathrm{p}<0.01, *$ indicates $0.05<\mathrm{p}<0.01$ 
Table 5. The Effect of Eligibility for Public Insurance on Private Group Health Insurance Coverage and Private Non-Group Health Insurance Coverage, IV Results for Full Sample and $100-200 \%$ FPL Children

\begin{tabular}{|c|c|c|c|c|}
\hline & \multicolumn{2}{|c|}{ Full Sample } & \multicolumn{2}{|c|}{$100-200 \%$ FPL } \\
\hline & (1) & (2) & (3) & (4) \\
\hline \multicolumn{5}{|l|}{ Private Non-Group Insurance } \\
\hline Eligible for public insurance & $\begin{array}{c}0.024^{*} \\
(0.009)\end{array}$ & ---- & $\begin{array}{l}0.019 * * \\
(0.006)\end{array}$ & ---- \\
\hline Eligible for Medicaid & ---- & $\begin{array}{c}0.027^{*} \\
(0.011)\end{array}$ & --- & $\begin{array}{c}0.017 \\
(0.009)\end{array}$ \\
\hline Eligible for stand-alone program & ---- & $\begin{array}{c}0.020 \\
(0.012)\end{array}$ & ---- & $\begin{array}{l}0.021^{* *} \\
(0.006)\end{array}$ \\
\hline $\mathrm{R}^{2}$ & 0.053 & 0.053 & 0.067 & 0.067 \\
\hline \multicolumn{5}{|l|}{ Private Group Insurance } \\
\hline Eligible for public insurance & $\begin{array}{c}-0.019 \\
(0.014)\end{array}$ & ----- & $\begin{array}{c}-0.027 * * \\
(0.010)\end{array}$ & ---- \\
\hline Eligible for Medicaid & ----- & $\begin{array}{c}-0.021 \\
(0.017)\end{array}$ & --- & $\begin{array}{c}-0.037^{*} \\
(0.015)\end{array}$ \\
\hline Eligible for stand-alone program & ----- & $\begin{array}{c}-0.010 \\
(0.018)\end{array}$ & ---- & $\begin{array}{c}-0.025^{*} \\
(0.011)\end{array}$ \\
\hline $\mathrm{R}^{2}$ & 0.346 & 0.345 & 0.157 & 0.160 \\
\hline Sample size & \multicolumn{2}{|c|}{190,257} & \multicolumn{2}{|c|}{42,991} \\
\hline \multicolumn{5}{|c|}{$\begin{array}{l}\text { Notes: Results are based on regressions using March CPS data from } 1997 \text { to } 2001 \text {. Models (1) and (3) pool } \\
\text { Medicaid and stand-alone eligibility and models (2) and (4) separate eligibility for Medicaid and stand-alone } \\
\text { programs. All regressions control for AFDC/TANF caseload, number of person in the household, race, number of } \\
\text { parents present and their gender, number of workers in the household, whether any in household works for a large } \\
\text { firm ( }>50 \text { employees), education of parents, number of people in household in fair or poor health, MSA residence, } \\
\text { foreign birth, age dummies for each age } 1-18 \text {, time dummies, and state dummies. Standard errors in parentheses. } \\
* * \text { indicates } p<0.01, * \text { indicates } 0.05<\mathrm{p}<0.01\end{array}$} \\
\hline
\end{tabular}


Table 6. Estimates of Take-Up and Crowd-Out Associated with SCHIP Expansions Under Different Assumptions

\begin{tabular}{|c|c|c|c|c|}
\hline & \multicolumn{2}{|c|}{ Full Sample } & \multicolumn{2}{|c|}{$100-200 \%$ FPL } \\
\hline Assumptions & Percentage & $\begin{array}{l}\text { Number of } \\
\text { Children } \\
(1,000 \mathrm{~s})\end{array}$ & Percentage & $\begin{array}{l}\text { Number of } \\
\text { Children } \\
(1,000 \mathrm{~s})\end{array}$ \\
\hline \multicolumn{5}{|l|}{ Private Coverage Variable is Accurate } \\
\hline Take-up among income eligible & $8.1 \%$ & 1,029 & $3.5 \%$ & 344 \\
\hline Take-up among income eligible uninsured ${ }^{\mathrm{a}}$ & $33.3 \%$ & 1,029 & $14.4 \%$ & 344 \\
\hline \multicolumn{5}{|l|}{ Crowd-Out ${ }^{\mathrm{b}}$ : } \\
\hline Lower point estimate & $0.0 \%$ & 0 & $0.0 \%$ & 0 \\
\hline Higher point estimate & $7.4 \%$ & 76 & $20.0 \%$ & 69 \\
\hline \multicolumn{5}{|l|}{$\begin{array}{l}\text { Increased Non-Group Coverage is result of } \\
\text { SCHIP }^{c}\end{array}$} \\
\hline Take-up among income eligible & $10.5 \%$ & 1,333 & $5.4 \%$ & 530 \\
\hline Take-up among income eligible uninsured ${ }^{\mathrm{a}}$ & $43.1 \%$ & 1,333 & $22.2 \%$ & 530 \\
\hline \multicolumn{5}{|l|}{ Crowd-Out ${ }^{\mathrm{b}}$ : } \\
\hline Lower point estimate & $18.1 \%$ & 241 & $35.2 \%$ & 186 \\
\hline Higher point estimate & $28.6 \%$ & 381 & $50.0 \%$ & 265 \\
\hline \multicolumn{5}{|c|}{$\begin{array}{l}{ }^{a} \text { Hypothetical calculation assuming that the increase in public enrollment came from children who were uninsured. } \\
\text { b Crowd out is computed two alternative ways: once as the ratio of the decrease in private coverage to the increase in } \\
\text { public coverage, and again as the portion of the increase in public coverage not accounted for by the decrease in } \\
\text { uninsurance. }\end{array}$} \\
\hline
\end{tabular}

